\title{
Correction to: Re-imagining the Art School
}

\section{Correction to:}

N. Mulholland, Re-imagining the Art School,

Creativity, Education and the Arts, https://doi.org/10.1007/978-3-030-20629-1

The book was inadvertently published with an incorrect spelling of the author name, which has now been changed from "Dandoff" to "Danoff" in Chapters 5, 6, 7 and Backmatter.

The updated version of these chapters can be found at https://doi.org/10.1007/978-3-030-20629-1_5 https://doi.org/10.1007/978-3-030-20629-1_6 https://doi.org/10.1007/978-3-030-20629-1_7 https://doi.org/10.1007/978-3-030-20629-1

(C) The Author(s) 2019

N. Mulholland, Re-imagining the Art School, Creativity, Education and the Arts, https://doi.org/10.1007/978-3-030-20629-1_8 